
Científicas (CSIC), POB 202, 50080 Zaragoza, Spain.

*Corresponding author.

Received. 1994; accepted......... 


\section{ACKNOWLEDGMENTS}

3 The authors wish to thank the Consejo Asesor de Investigación-DGA (Grants nos. PCA-9/89 and 4 BCA-35/89) and the Comisión Interministerial de Ciencia y Tecnología (Grant no. AGF93-06135 C02-02) Spanish Agencies for financial support. They are grateful to Dr. S.R. Yates for providing 6 the geostatistical software and also to Dr. A. Martínez-Cob and D. Quílez for their constructive 7 comments on the draft manuscript.

8 


\title{
EFFICIENCY OF AN INCOMPLETE BLOCK DESIGN
} BASED ON GEOSTATISTICS FOR TILLAGE EXPERIMENTS

\begin{abstract}
Spatial dependence of soil properties often reduces the power of conventional statistical methods to detect treatment differences. Control of adverse effects of soil variability is of special interest in long-term experiments when small and slowly developing treatment effects are generally expected to occur, as in tillage research. The main objective of this study was to evaluate the ability of an incomplete block design based on geostatistical concepts to improve the precision of a conservation tillage experiment conducted at four sites in Aragón, NE Spain. A preliminary geostatistical characterization of plow layer variability at these sites showed that, in most instances, soil water content and silt plus clay content were spatially dependent. Maps of kriged estimates of these properties were used to locate the tillage plots according to the proposed design. Using incomplete blocks of size two, the method estimates treatment effects by making short-distance comparisons and insures spatially-balanced treatment contrasts through fixed comparison distances. This design was compared with a complete block design using soil and crop data obtained during the first two growing seasons of the tillage experiment. The results of a total of one thousand and fifty analysis of variance comparisons revealed that the incomplete block design was, on the average, 24\% more efficient than the complete block design. The use of incomplete blocks reduced the average error mean square by $33 \%$ and increased the number of cases with significant tillage treatment differences by $25 \%$ compared to the use of complete blocks.
\end{abstract}




\section{INTRODUCTION}

Inherent soil spatial variability has long been recognized as one of the major factors that adversely affects the outcome of field experiments. Agricultural and soil research usually involves large plots or large numbers of treatments and, therefore, large blocks which are rarely uniform. In such cases, soil heterogeneity can result in low efficiency of the randomized complete block design due to a large error term (Mulla et al., 1990; Brownie et al., 1993). Likewise, when local heterogeneity is spatially structured, randomization and replication alone do not ensure that all treatment comparisons are made with equal precision (van Es and van Es, 1993). Thus, spatial dependence of observations has been cited as a major reason for nonsignificant treatment differences using a classical complete block analysis in tillage and yield experiments (Roseberg and McCoy, 1988; Bhatti et al., 1991; Ball et al., 1993). Control of these effects of soil variability is of special interest in long-term experiments examining treatments that are generally expected to have relatively moderate and slowly developing effects (Frye and Thomas, 1991).

Several designs and analysis techniques have been proposed as alternatives to approach the soil variability problem. Among them are nearest neighbor analysis and trend analysis. Brownie et al.

17 (1993) reviewed the properties, merits and drawbacks of both methods and described some variations on each. Although improvement in precision has been reported when comparing these

19 methods with conventional designs (Samra et al., 1992; Brownie et al., 1993; Stroup et al., 1994), they are not widely adopted. Another approach to increase precision is to reduce block size through the use of incomplete block designs (Yates, 1936). Although they were initially recommended for reducing error variances, they may also provide a method for insuring spatially-balanced treatment comparisons. Based on the theory of regionalized variables, van Es et al. (1989) developed an experimental design using incomplete blocks of size two (IB). This method is specially applicable to tillage research and the relative simplicity of its design and analysis of variance appears to be an 
important advantage.

All of the above considerations were of major concern to the authors in planning a long-term field research project in order to determine the feasibility of conservation tillage systems as a strategy to improve soil and water conservation in different dryland cereal-growing areas of Aragón, northeastern Spain. In this region, water is the main limiting factor for crop production and land is affected by high annual rates of topsoil losses by both wind and water erosion during the fallow periods (López, 1993).

The purpose of this study was (i) to evaluate, by means of geostatistical techniques, soil spatial variability in the plow layer prior to the establishment of the tillage experiments and (ii) to compare the relative efficiency of the IB design over a traditional complete block design (CB) using soil and crop data from the first two experimental growing seasons.

\section{MATERIALS AND METHODS}

\section{Experimental sites}

Four sites representing the main dryland barley (Hordeum vulgare L.) production areas in Aragon, NE Spain, were selected to conduct the long-term conservation tillage research. Two sites, Peñaflor and Zuera, were located at the Estación Experimental de Aula Dei, CSIC, and Diputación General de Aragón experimental farms, respectively, both in the Zaragoza province. The soils are a loam (fine-loamy, mixed, thermic Xerollic Calciorthid) at Peñaflor and a silty loam (fine-silty, mixed, thermic Xerollic Calciorthid) at Zuera. The other two sites, Híjar and Banastás, were located on collaborating commercial farms in the Teruel and Huesca provinces, respectively. The soil at the Híjar site is a loam (fine-loamy, mixed, thermic Xerollic Calciorthid) and a silty clay loam (finesilty, mixed, thermic Fluventic Ustochrept) at Banastás. While the Híjar site is classified as very gently sloping ( $<2 \%)$, in the N-S direction, the others are nearly level. The climate of the study area is mostly semiarid and with sporadic and highly-variable precipitation. Average annual rainfall 
ranges from $340 \mathrm{~mm}$ in Peñaflor to $600 \mathrm{~mm}$ in Banastás. A more detailed description of soil and climate characteristics is given in López (1993). All sites have been conventionally tilled with barley grown under continuous cropping (Banastás site) and cereal-fallow rotation (Peñaflor, Zuera, and Híjar sites) for at least the previous 10 yr.

\section{Geostatistical Analyses}

Soil properties considered for the characterization of the plow layer, prior to the establishment of experimental plots in the summer of 1990, were the gravimetric water content $(w)$ and the fraction of particles less than $50 \mu \mathrm{m}$ (silt plus clay fraction, $\mathrm{S}+\mathrm{C}$ ) which is the main textural component responsible for plant-available water. These properties are easily measured in most soil laboratories and have been traditionally used to identify boundary locations between different soil types. Field sampling was laid out in the apparently uniform area available at each site, following the spatial schemes shown in Fig. 1. In order to obtain sample pairs at distances shorter than those provided by sampling at the nodes of a regular $20 \times 20$ m or $25 \times 25$ m grid, additional samples were collected along two perpendicular transects (lag distances of 5, 10, and $15 \mathrm{~m}$ ) at the Peñaflor and Zuera sites. At each sampling point, a disturbed soil sample was taken by augering at two depths in the plow layer $(0-20 \mathrm{~cm}$ and 20-40 cm). Immediately after collecting the samples, they were taken to the laboratory to determine $w$ by oven drying at $105^{\circ} \mathrm{C}$ and $\mathrm{S}+\mathrm{C}$ by the pipette method (Gee and Bauder, 1986). Sampling at each site was carried out in a single day.

The spatial structure of $w$ and $\mathrm{S}+\mathrm{C}$ was determined using standard geostatistical techniques. Two steps were involved in this analysis: i) computation of experimental semivariograms and fitting them to theoretical models; and ii) data interpolation by kriging and display of the spatial patterns using contour maps. Detailed theory and applications of these techniques can be found elsewhere (Vieira et al., 1983; Warrick et al., 1986). The semivariograms for the Peñaflor and Zuera sites were computed for a maximum distance of $85 \mathrm{~m}$ and $70 \mathrm{~m}$, respectively, approximately half of the 
maximum distance between sampling points (Journel and Huijbregts, 1978). This criterion was not applied for the other two locations, which had a lower number of sampling points. In order to increase the number of points of the experimental semivariograms in these cases, the maximum distance for semivariogram computation was fixed to 112 m and 90 m at the Híjar and Banastás sites, respectively. Semivariances for greater distances were not computed because the numbers of sample pairs were not great enough to obtain a reliable semivariance (Journel and Huijbregts, 1978). Model coefficients (nugget effect, sill, and range) were validated by a jackniffing technique and values of the reduced mean, $\mathrm{R} \mu$, close to zero and reduced variance, $\mathrm{R} \sigma^{2}$, close to unity were used as indicators for selecting the best model (Vauclin et al., 1983). In order to detect anisotropy, four directional semivariograms were calculated at angles of $0^{\circ}, 45^{\circ}, 90^{\circ}$, and $135^{\circ}$. The horizontal direction was set to $0^{\circ}$ and the vertical direction to $90^{\circ}$. In the cases where anisotropy was found, the anisotropy ratio (David, 1977) was included in the kriging process. The validated semivariograms were then used for interpolation using ordinary kriging. Estimates of $w$ and $\mathrm{S}+\mathrm{C}$ were calculated at the corners of a 5 x 5 m grid superimposed over the fields initially sampled. In the Banastás site the interpolation was extended to a total area of 125 x $100 \mathrm{~m}$. The kriging system used the ten nearest sample points to the point to be estimated within a maximum radius equal to the range of the semivariogram models. All the geostatistical computations were performed using the GEOPACK software package (Yates, 1989). Contour maps of $w$ and S+C from each site and soil depth were made using the program SURFER (1985).

\section{Experimental Design}

Fig. 2 shows the IB design used at the four field sites. It was adapted from van Es et al. (1989) to our study involving three tillage treatments: conventional tillage (CT), reduced tillage (RT), and notillage (NT). The CT treatment consisted of moldboard plowing to 30-40 cm depth in summer followed by secondary tillage to $10-15 \mathrm{~cm}$ with harrow or cultivator in fall. In the RT treatment, the 
1 primary tillage operation was chisel plowing to $25-30 \mathrm{~cm}$ depth in summer followed, as for CT, by fall harrow or cultivator tillage. The NT plots were not tilled and weeds were controlled by herbicides. A more detailed description of soil and crop management for each treatment is given in López (1993).

As it is indicated in Fig. 2, each pair of treatment plots makes up an incomplete block of size 2 (demarcated by dotted lines). Thus, each pair of treatments (i.e., CT-RT, CT-NT, and RT-NT) form an incomplete block in three locations. To insure a balanced design, the CT treatment must be replicated four times, once more than the RT and NT treatments. Two large blocks of plots, like the one shown in Fig. 2, with a separation of $10 \mathrm{~m}$ were established at the Peñaflor, Zuera, and Híjar sites in order to compare the three tillage treatments under both continuous barley and barley-fallow rotation; at the Banastás site, where only the traditional continuous cropping system was considered, only one large block of plots was established. Due to less available space at Peñaflor, the plot length

13 at this site was $33.5 \mathrm{~m}$.

14 Data used to evaluate the IB design were those obtained during the first two growing seasons 15 (1990-91 and 1991-92) of the tillage study. Field data consisted of volumetric soil water content $(\theta)$, 16 soil penetration resistance (PR), and different parameters of plant growth and yield (seed depth, 17 percentage emergence, plant height, leaf area index, above-ground dry matter, tillers/plant, 18 spikes $/ \mathrm{m}^{2}$, kernels/spike, kernel weight, and grain yield). Soil water content was determined 19 gravimetrically to a depth of $80 \mathrm{~cm}$ in $10 \mathrm{~cm}$ increments and converted to a volumetric basis using 20 bulk densities determined by the core method for the same soil layers. The PR was recorded at $5 \mathrm{~cm}$ 21 intervals to a depth of $40 \mathrm{~cm}$ using a recording penetrometer (06.02 Penetrograph Stiboka, 22 Eijkelkamp). Plant samples were taken by hand harvesting $50 \mathrm{~cm}$ row lengths. Soil and crop 23 measurements were simultaneously made four to five times during each growing season at different 24 crop growth stages. In addition, soil water storage (S) to a depth of $80 \mathrm{~cm}$ and evapotranspiration 25 (ET) estimates were also used as test data. ET was calculated by soil water balance from rainfall data 
and changes in S over the different time periods delimited by the dates of $\theta$ determination.

Within each incomplete block were delimited regions for soil and crop observations (Fig. 2). Two observation points exist in each region, one per treatment. The distance between points was $5 \mathrm{~m}$ for all regions. One region per incomplete block was used for soil properties. For crop parameters two regions were considered with the exception of the Peñaflor and Híjar sites where only one region was used during the 1991-92 growing season. With this sampling scheme, comparisons of treatments are made at short and constant distances, thus insuring that the contrasts are spatially balanced. More details about this design and the underlying geostatistical concepts on which it is based can be found in van Es et al. (1989).

In summary, the IB design provides (Fig. 2):

9 incomplete blocks (3 blocks per each pair CT-RT, CT-NT, and RT-NT);

1 x $9=9$ observation regions for soil parameters;

2 × 9 = 18 observation regions for crop parameters;

2 x 1 x $9=18$ observation points for soil parameters; and

$2 \times 2 \times 9=36$ observation points for crop parameters.

The treatment allocations also allow for a CB analysis. Thus, excluding the 10th CT plot (Fig. 2), we obtain:

3 complete blocks (including 3 treatments each);

3 x 3 = 9 plots (3 per treatment);

$2 \times 9=18$ observations for soil parameters; and

$4 \times 9=36$ observation for crop parameters.

All data were analyzed using analysis of variance for IB (IB-ANOVA) as well as the conventional analysis (CB-ANOVA) assuming randomization on the assignment of treatments to plots. In the IB-ANOVA, treatment effects were estimated using an intrablock analysis (van Es et al., 1989). In this method, all inferences are based on comparisons made within the blocks, i.e., at short 
distances. Treatment effects are adjusted for the differences between blocks because treatments and blocks are not orthogonal. The error, or intrablock residual, is assumed to be normally and independently distributed with mean 0 and variance $\sigma^{2}$. Table 1 shows the IB-ANOVA, where $t, b$, and $r$ are, respectively, the total number of treatments (3), blocks (9), and regions per block (1 or 2). The sums of squares for blocks and sampling error are computed in the standard way. The sum of squares for treatments, adjusted for blocks, is $\Sigma Q_{i}{ }^{2} / 2 \lambda t r$, where $\lambda$ is the number of times each pair of treatments occurs together in a block ( 3 in this experiment) and $Q_{i}$ is given by $Q_{i}=2 T_{i}-B_{i}$, where $T_{i}$ is the total of all plots receiving the $i^{\text {th }}$ treatment and $B_{i}$ is the total of all blocks containing the $i^{\text {th }}$ treatment. To test for treatment differences the adjusted treatment mean square was divided by the experimental error mean square. The reader is referred once more to van Es et al. (1989) for more detailed comments about this method of analysis. Duncan's multiple range was used to compare among treatment means. For the calculation of the least significant difference, the standard error for the IB design was obtained following the procedure described by Cochran and Cox (1950) and Li (1969). Computations for IB-ANOVA and CB-ANOVA were performed using a FORTRAN-77 specific program and the BMDP-8V program (Jennrich and Sampson, 1990), respectively.

The relative efficiency (RE) of the IB design to the CB design was computed as the percentage ratio of the average experimental error mean square for the $\mathrm{CB}$ design $\left(\mathrm{MSE}_{\mathrm{CB}}\right)$ to that of the IB design (MSE $\mathrm{IB}_{\mathrm{IB}}$ ), following the procedure given by Cochran and Cox (1950). The adjustment factor for different error degrees of freedom was 1.12. The efficiency factor of a balanced incomplete block design (Li, 1969; Scheffé, 1970), i.e., 0.75 in our case, was included in the calculation of RE as a multiplying factor. This factor indicates the lower limit of the efficiency of IB relative to the use of $\mathrm{CB}$ and is based on the assumption that error variance is of the same magnitude for both incomplete blocks of size 2 and complete blocks of size 3 (Li, 1969; Scheffé, 1970). 


\section{Spatial Variablity of the Plow Layer}

The descriptive statistics for all the data sets are shown in Table 2. Normal distribution of data was tested using the Kolmogorov-Smirnov test. The fact that the test statistic, $\mathrm{KS}_{\mathrm{t}}$, was always less than the critical value, $\mathrm{KS}_{\mathrm{C}}$, for a probability level of 0.1 (Yates and Warrick, 1987), indicated that all observations were normally distributed. The relatively small coefficients of variation (CV), specially for S+C (Table 2), were of the same order of magnitude as those reported in the literature for surface soil of agricultural fields and showed that the fields were relatively uniform. On the other hand, $t$-tests indicated significant differences $(P<0.05)$ between the means of the two soil layers (0-20 and 20-40 cm) for $w$ at all sites. In contrast, no depth differences existed for $\mathrm{S}+\mathrm{C}$, which is likely due to annual deep plowing thus creating a uniform layer to a depth of $30-40 \mathrm{~cm}$.

Parameters of the different models fitted to the experimental semivariograms for each soil property, depth, and site are listed in Table 3. As indicated, $\mathrm{R} \mu$ and $\mathrm{R} \sigma^{2}$ values were used as the main criteria to accept a particular model as adequate. A nugget effect was present in most of the models, specially for $w$. Semivariograms for $w$ at Peñaflor $(0-20 \mathrm{~cm}$ and 20-40 cm) and Banastás (20-40 cm) were pure nugget effect (Table 3). This model indicates that there is no spatial dependence at the scale of investigation and all the variation occurs within the smallest sampling distance. Therefore, $w$ in these cases can be adequately characterized by the mean and sample variance (Table 2). Although there is an apparent lack of stationarity, inspection of the semivariogram for $w(20-40 \mathrm{~cm})$ at the Híjar site also indicated a large nugget variance (88\% of the total variability for the maximum distance of semivariogram computation). A possible reason for the weak or nonexistent spatial dependence of $w$ may be the destruction of natural soil structure by tillage resulting in a more or less uniformly-loosened soil. Voltz and Bornand (1988) and Burden and Selim (1989) observed similar random behavior for soil moisture retention at different suctions in the plow layer. Soil disturbance by both tillage and vehicle traffic seems to create an important variability in soil porosity at short distances (Mohanty et al., 1991; Poier and Richter, 1992) which 
might mask natural soil variability. In contrast, $\mathrm{S}+\mathrm{C}$ was spatially related in all cases with ranges going from $27 \mathrm{~m}$ to $127 \mathrm{~m}$ (Table 3). With the possible exception of the Híjar site, where S+C had a relatively high nugget variance, the nugget effect was either nonexistent (Peñaflor site) or represented only a small portion of total variance (4-11\%). The different spatial behavior between $w$ and $\mathrm{S}+\mathrm{C}$ may be explained by the fact that $\mathrm{S}+\mathrm{C}$, as textural component, is a static property, while $w$ is the result of the processes of wetting and drying which depend not only on soil texture but also on soil structure and topographic characteristics. This is supported by the results of the correlation analyses between $w$ and $\mathrm{S}+\mathrm{C}$ for each depth (Table 4). Although a significant correlation $(P<0.05)$ was found for the two depths at three of the sites, the coefficients of determination $\left(\mathrm{r}^{2}\right)$ ranged from 0.108 to 0.392 . Thus, at the best, only $39 \%$ of the $w$ variation would be explained by S+C changes. Nevertheless, the similarity between the coefficients of theoretical semivariograms for both properties obtained for each of the two depths (Table 3) makes evident the mixing effect of Ap horizons by tillage operations.

Visual inspection of the directional semivariograms could indicate anisotropy for $w(0-20 \mathrm{~cm})$ at the Híjar site and S+C (0-20 and 20-40 cm) at the Banastás site with the greatest variation occurring in the N-S direction and the smallest in the E-W direction in the three cases (Fig. 3). The significant linear trend noticed for $w$ in the N-S direction at Híjar site (Fig. 3A) was reflected in the linear model without sill fitted to the experimental semivariogram (Table 3). However, if the number of sampling points is low, as it occurs at the Híjar and Banastás sites, the analysis of anisotropy can be seriously limited (Webster and Oliver, 1990). The fact that at the Híjar site the direction of greatest variation was coincident with the slope direction supported the assumption of anisotropic variation for the above mentioned cases. Nevertheless, to identify anisotropy satisfactorily a much more intensive sampling would be needed.

S+C semivariograms at Híjar and Banastás sites exhibited the largest ranges of influence among all S+C data sets (Table 3). A gradual increase of the semivariance over long distances, close to or 
larger than the maximum distance computed, could suggest the existence of a trend. However, there was no clear evidence of non-stationarity. Jackniffing results indicated that these $S+C$ data were best fitted by the gaussian model. Thus, it was assumed that the semivariance increased in a nonlinear manner and reached a sill at separation distances ranging from $73 \mathrm{~m}$ to $127 \mathrm{~m}$ (Table 3).

According to Vieira et al. (1992), the usefulness of jackniffing is limited when the number of samples is low and this could be the case for the Híjar and Banastás sites. Due to the possibility for nonstationarity, it was decided to apply the sliding neighborhoods method (Cooper and Istok, 1988) for the estimation of unknown $w$ and $\mathrm{S}+\mathrm{C}$ values in these sites. In this method, kriging is performed using only those sample values that lie within the neighborhood of the point to be estimated. This procedure allows us to smooth the stationarity conditions and then assume that at any point in the field the mean value of a given property is constant for some radius about that point (Cooper and Istok, 1988). In our case, the maximum search radius was set at $56 \mathrm{~m}$ for $w$ and $\mathrm{S}+\mathrm{C}$ at the Híjar site, and at $45 \mathrm{~m}$ for $\mathrm{S}+\mathrm{C}$ at the Banastás site, after confirming that the kriging variances did not increase significantly.

The contour maps of kriged $w$ and $\mathrm{S}+\mathrm{C}$ estimates were used to locate within the fields the experimental plots according to the IB design (Fig. 2). However, more weight was given to the S+C maps. It is expected that $\mathrm{S}+\mathrm{C}$, as a soil textural component, does not change with time and shows a greater temporal stability than $w$. In addition, $w$ exhibited in some cases either a completely random spatial distribution or a large nugget variance.

Figs. 4 and 5 show the contour maps of $\mathrm{S}+\mathrm{C}$ at the four sites. Hatching represents the experimental areas selected for the tillage study under continuous cropping and cereal-fallow rotation at the Peñaflor (Fig. 4A), Zuera (Fig. 4C), and Híjar sites (Fig. 5A) and only under continuous cropping in the Banastás site (Fig. 5C). The fact that $\mathrm{S}+\mathrm{C}$ showed a relatively homogeneous distribution over the entire field, with similar patterns in the two horizons studied, facilitated the location of these experimental areas. The two following general criteria were taken 
1 into account in this selection process: i) similar soil conditions in the two large blocks of plots for comparison of continuous cropping and cereal-fallow rotation; ii) smaller plot dimension in the direction of maximum variation to reduce heterogeneity within the plot where gradients were detected. Once these criteria were fulfilled, practical aspects, such as easy access for personnel and machinery, were also considered. The location of the experimental areas in the most homogeneous regions of the fields was not a major selection criterion because the IB design a priori controls the existing soil variability.

This preliminary geostatistical survey evidenced how, in most cases analyzed, the soil properties selected, specially $S+C$, exhibited spatial dependence. This fact supports the decision of applying the IB design to our long-term tillage research. relative efficiency of IB as compared to $\mathrm{CB}$, and (iii) ability to detect tillage treatment differences. with the nearly unchanged treatment mean square (2707.65 and 2761.60, respectively for IB and CB) indicated a greater power of IB for testing treatment effects. However, more precise information in relation to the comparison between these specific designs is obtained from RE values. The average values of RE were larger than $100 \%$ at the four field sites (Table 5), indicating that the incomplete blocks were more homogeneous than the complete blocks and, therefore, that the IB design was more accurate. Note that the average gain of efficiency at the Zuera site was only $8 \%$ as compared to the $28-30 \%$ for the other sites. This small gain could be due to a weak or nonexistent spatial structure in the distribution of soil and crop properties within the experimental field. In fact, 
the preliminary geostatistical study at the Zuera site showed that $S+C$ overall had the lowest values of semivariance and range of influence. In contrast, semivariograms for the cases of the Híjar and Banastás sites, with a gain of efficiency of $30 \%$, showed in general larger spatial dependence and even a field trend (Híjar). These results support the idea that a relative improvement in efficiency is only obtained when field observations are spatially structured (Samra et al., 1992; Stroup et al., 1994). Likewise, van Es and van Es (1993) demonstrated that the problem of spatial inequity of treatment comparisons using the classical CB design may not have serious effects on the outcome of the experiment if the property exhibits non important spatial autocorrelation.

It is interesting to note that the smallest values of RE corresponded to the crop variable (Table 5). This variable represents all parameters of barley growth and yield measured during the experimental period. With the exception of the Híjar site, the use of the IB design implied a loss of efficiency of 4-6\%. One reason for these results might be that the spatially variable soil properties did not substantially influence crop variability or, in other words, the crop did not show the same degree of spatial dependence as the soil. Another possible reason may be the fact that the number of observations used for crop characterization was twice that used for soil characterization for most sampling dates. Increasing the number of replications in a classical CB design reduces the problem of unequal distances of treatment comparisons, although it does not eliminate it. This is due to the fact that the mean distance of comparisons remains the same, but the variance is reduced (van Es and van Es, 1993), which can increase the efficiency of the CB design. This idea seems to be confirmed by comparing RE for the crop variable between the two growing seasons at the Peñaflor and Híjar sites. In the 1990-91 growing season, with four observations per experimental plot, RE was only 77\% and 95\%, respectively, at Peñaflor and Híjar, while in the 1991-92 season, with only two replications, RE reached values of $110 \%$ and $113 \%$, respectively.

The IB design was, on the average, 24\% more efficient than the CB design. This gain of efficiency was reflected in the greater ability of the IB design to distinguish differences among 
tillage treatments (Table 5). Thus, the total number of cases with significant treatment differences was $25 \%$ higher with the IB-ANOVA than with the CB-ANOVA. In our opinion, this percentage acquires more importance when it is considered that, overall, there were no strong responses to applied tillage systems, as may be expected in the first years of long-term experiments. Actually, only $37 \%$ of the total IB-ANOVAs showed statistically significant treatment effects. These results also suggest that the CB-ANOVA tends to underestimate treatment effects relative to the larger error term.

Using wheat yield data from a uniformity trial and applying an IB design, van Es et al. (1989) obtained a reduction in the average MSE of $44 \%$ and a gain of efficiency of $21 \%$ relative to CB design. This improvement was of similar magnitude to that of the present study. There was no reason to expect a larger increase in efficiency because of the relative uniformity of the four experimental fields.

In conclusion, this study shows that the precision of tillage experiments can be improved using IB designs without necessarily increasing the cost of experimentation. With this method, the adverse effects of soil spatial variability are reduced by making short distance treatment comparisons. In addition, by keeping this distance constant, it is insured that all contrasts are made with equal precision (van Es et al., 1989). The suitability of the IB design and, therefore, its recommendation for soil and crop measurements in large-plot field experiments is clearly supported by results presented here. Furthermore, the application of this design appears to be of special interest in heterogeneous fields where a more substantial increase in efficiency may be expected. 

correlation from yield experiments. Soil Sci. Soc. Am. J. 55:1523-1528.

14 Brownie, C., D.T. Bowman, and J.W. Burton. 1993. Estimating spatial variation in analysis of data 15 from yield trials: a comparison of methods. Agron. J. 85:1244-1253.

16 Burden, D.S., and H.M. Selim. 1989. Correlation of spatially variable soil water retention for

19 York.

Cooper, R.M., and J.D. Istok. 1988. Geostatistics applied to groundwater contamination: I. 21 Methodology. J. Environ. Eng. ASCE 114:270-286.

22 David, M. 1977. Geostatistical ore reserve estimation. In Developments in Geomathematics 2.

23 Elsevier Scientific Publishing Company, New York, NJ.

24 Frye, W.W., and G.W. Thomas. 1991. Management of long-term field experiments. Agron. J. 25 83:38-44. 
Gee, G.W., and J.W. Bauder. 1986. Particle-size analysis. In A. Klute (ed.), Methods of soil analysis, Part 1, 2nd ed., Agronomy 9:383-411.

Jennrich, R., and P. Sampson. 1990. General mixed model analysis of variance-equal cell sizes. p. 1245-1261. In W.J. Dixon (ed.), Biomedical Computer Programs Statistical Software, University of California Press, Los Angeles, CA.

Journel, A.G. and Ch.J. Huijbregts. 1978. Mining Geostatistics. Academic Press, New York.

Li, C.C. 1969. Introduction to experimental statistics. McGraw-Hill, New York.

López, M.V. 1993. Soil and plant response to conservation tillage in rainfed barley production systems of Aragón (NE Spain). Ph.D. diss. University of Navarra, Pamplona, Spain (Diss. Abstr.).

Mohanty, B.P., R.S. Kanwar, and R. Horton. 1991. A robust-resistant approach to interpret spatial behavior of saturated hydraulic conductivity of a glacial till soil under no-tillage system. Water Resour. Res. 27:2979-2992.

Mulla, D.J., A.U. Bhatti, and R. Kunkel. 1990. Methods for removing spatial variability from field research trials. Adv. Soil Sci. 13:201-213.

Poier, K.R., and J. Richter. 1992. Spatial distribution of earthworms and soil properties in an arable loess soil. Soil Biol. Biochem. 24:1601-1608.

Roseberg, R.J., and E.L. McCoy. 1988. Time series analysis for statistical inferences in tillage experiments. Soil Sci. Soc. Am. J. 52:1771-1776.

Samra, J.S., R.K. Rajput, and V. Katyal. 1992. Structured heterogeneity of soil pH and grain yield of rice and wheat grown in a sodic soil. Agron. J. 84:877-881.

Scheffé, H. 1970. The analysis of variance. John Wiley \& Sons, New York.

Stroup, W.W., P. S. Baenziger, and D.K. Mulitze. 1994. Removing spatial variation from wheat yield trials: a comparison of methods. Crop Sci. 86:62-66.

SURFER. 1985. Version 2.00, Golden Software, Inc., Golden, CO. 
van Es, H.M., and C.L. van Es. 1993. Spatial nature of randomization and its effect on the outcome of field experiments. Agron. J. 85:420-428.

van Es, H.M., C.L. van Es, and D.K. Cassel. 1989. Application of regionalized variable theory to large-plot field experiments. Soil Sci. Soc. Am. J. 53:1178-1183.

Vauclin, M., S.R. Vieira, G. Vachaud, and D.R. Nielsen. 1983. The use of cokriging with limited field soil observations. Soil Sci. Soc. Am. J. 47:175-184.

Vieira, S.R., J.L. Hatfield, D.R. Nielsen, and J.W. Biggar. 1983. Geostatistical theory and application to variability of some agronomical properties. Hilgardia 51:1-75.

Vieira, S.R., O. Melo de Castro, and G. Clarke. 1992. Spatial variability of some soil physical properties in three soils of São Paulo, Brazil. Pesq. agropec. bras.., Brasília 27:333-341.

Voltz, M., and M. Bornand. 1988. Analyse de la variabilité spatiale des propriétés physiques du sol. p. 101-103. In R. Calvet (ed.), Etudes sur les transferts d'eau dans le système sol-plante-atmosphère, INRA, Paris, France.

Warrick, A.W., D.E. Myers, and D.R. Nielsen. 1986. Geostatistical methods applied to soil science. In A. Klute (ed.), Methods of soil analysis, Part 1, 2nd ed., Agronomy 9:53-82.

Webster, R., and M.A. Oliver. 1990. Statistical methods in soil and land resource survey. Oxford University Press. 316 p.

Yates, F. 1936. A new method of arranging variety trials involving a large number of varieties. J. Agric. Sci. 26:424-455.

Yates, S.R. 1989. GEOPACK: A geostatistical software system. p. 693-698 In Hydraulic Engineering '89. Proc. ASCE Nat'l Conf. on Hydraulic Engineering \& Int'l Symposium on

Sediment Transport Modeling, New Orleans, LA.

Yates, S.R., and A.W. Warrick. 1987. Estimating soil water content using cokriging. Soil Sci. Soc. Am. J. 51:23-30. 
12 Figure 1.- Field sampling scheme at Peñaflor (A), Zuera (B), Híjar (C), and Banastás (D) sites.

13 Circles indicate sampling locations.

15 Figure 2.- Experimental design for the tillage experiment at the four field sites (CT: conventional

16 tillage; RT: reduced tillage; NT: no-tillage). The squares indicate areas where soil and crop

17 observations were made.

19 Figure 3.- Directional semivariograms for gravimetric soil water content, $0-20 \mathrm{~cm}$, at Híjar site 20 (A), silt plus clay fraction, 0-20 cm, at Banastás site (B), and silt plus clay fraction, $20-40 \mathrm{~cm}$, 21 at Banastás site (C).

23 Figure 4.- Contour maps of kriged estimates of silt plus clay fraction at Peñaflor site from

25 depth (D). Hatching represents the experimental areas selected for the tillage study. 
2 Figure 5.- Contour maps of kriged estimates of silt plus clay fraction at Híjar site from 0-20 cm

3 depth (A) and 20-40 cm depth (B), and Banastás site from 0-20 cm depth (C) and 20-40 $\mathrm{cm}$

4 depth (D). Hatching represents the experimental areas selected for the tillage study. 


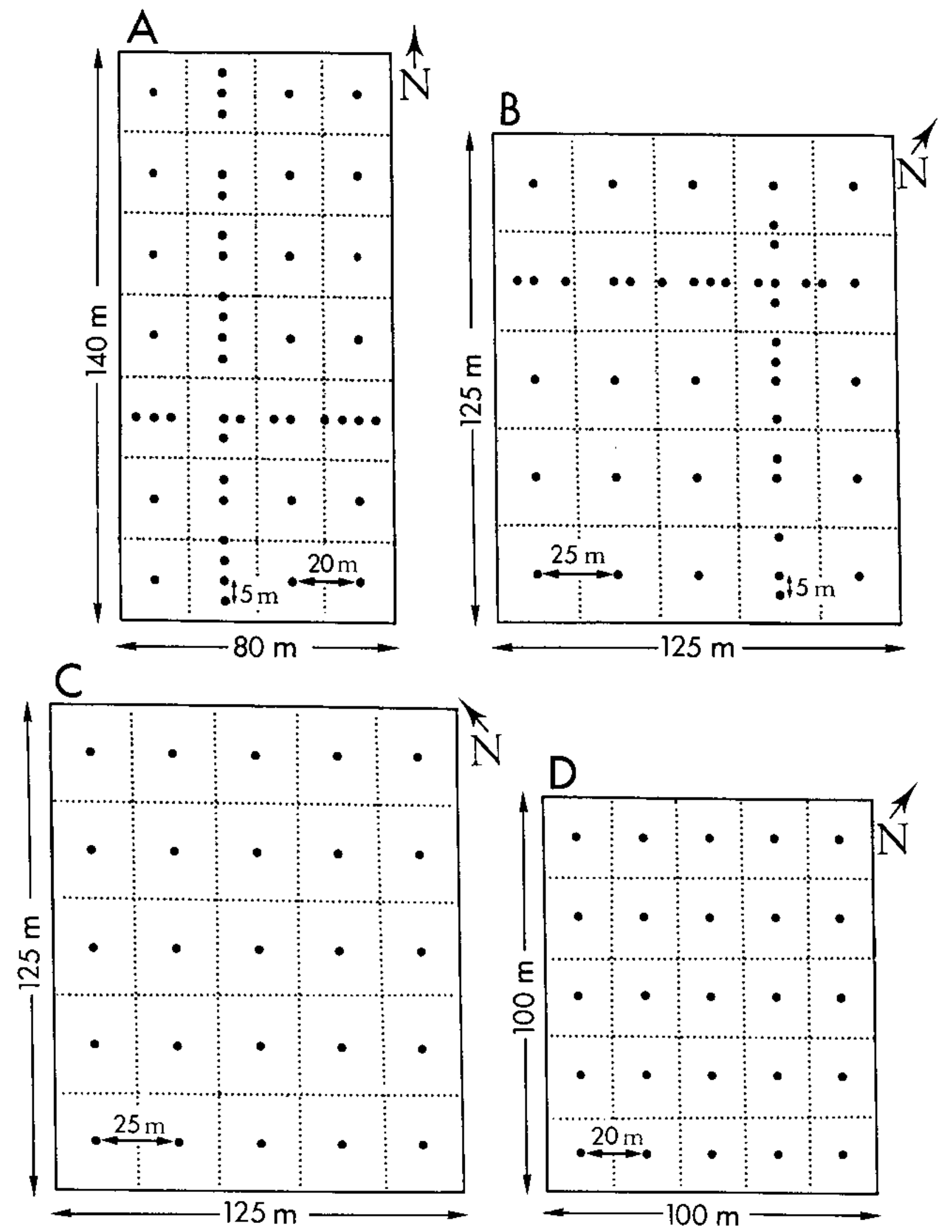

Fig. 1.

María V. López and José L. Arrúe

Efficiency of an Incomplete Block Design... 


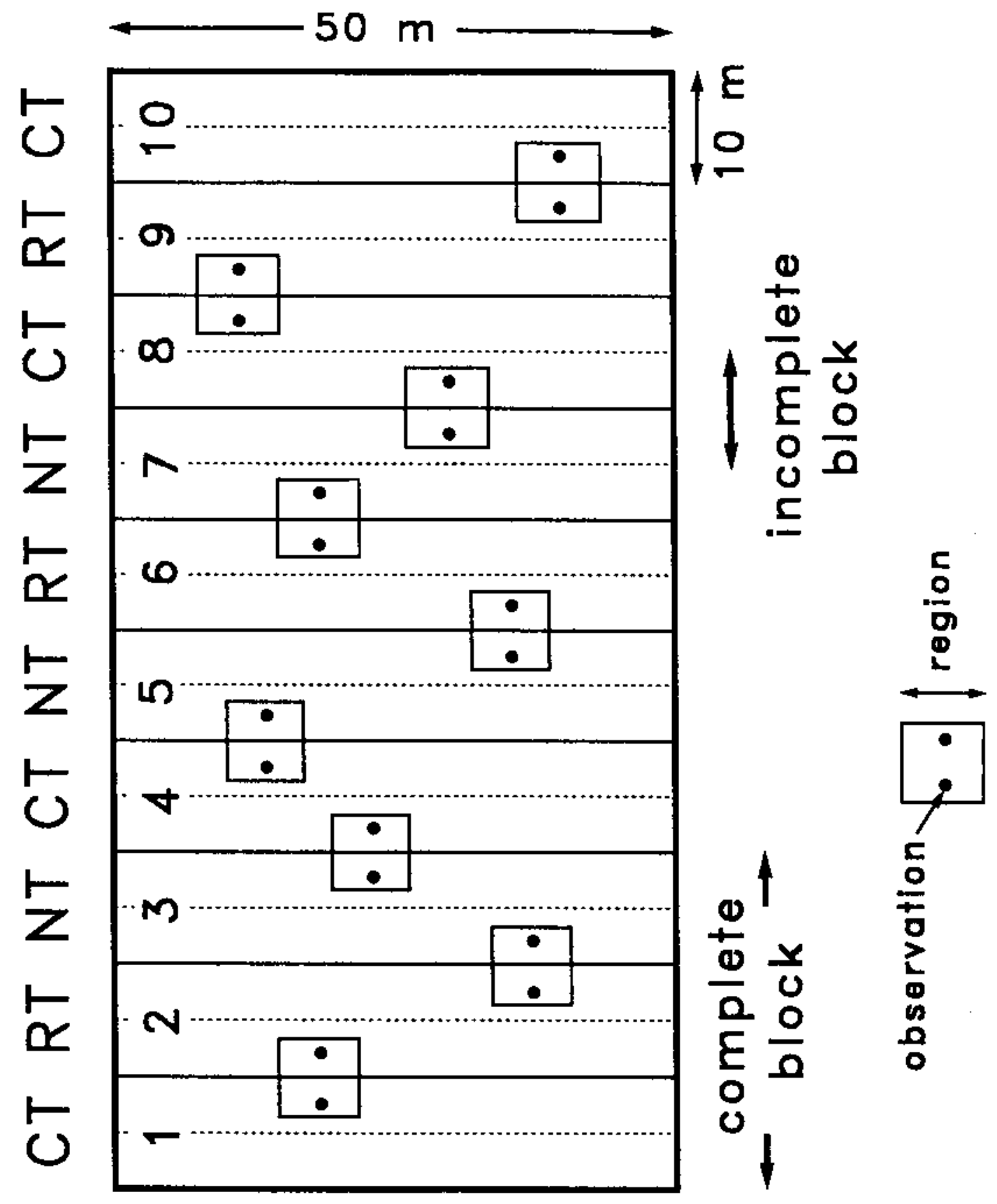

Fig. 2.

María V. López and José L. Arrúe

Efficiency of an Incomplete Block Design... 

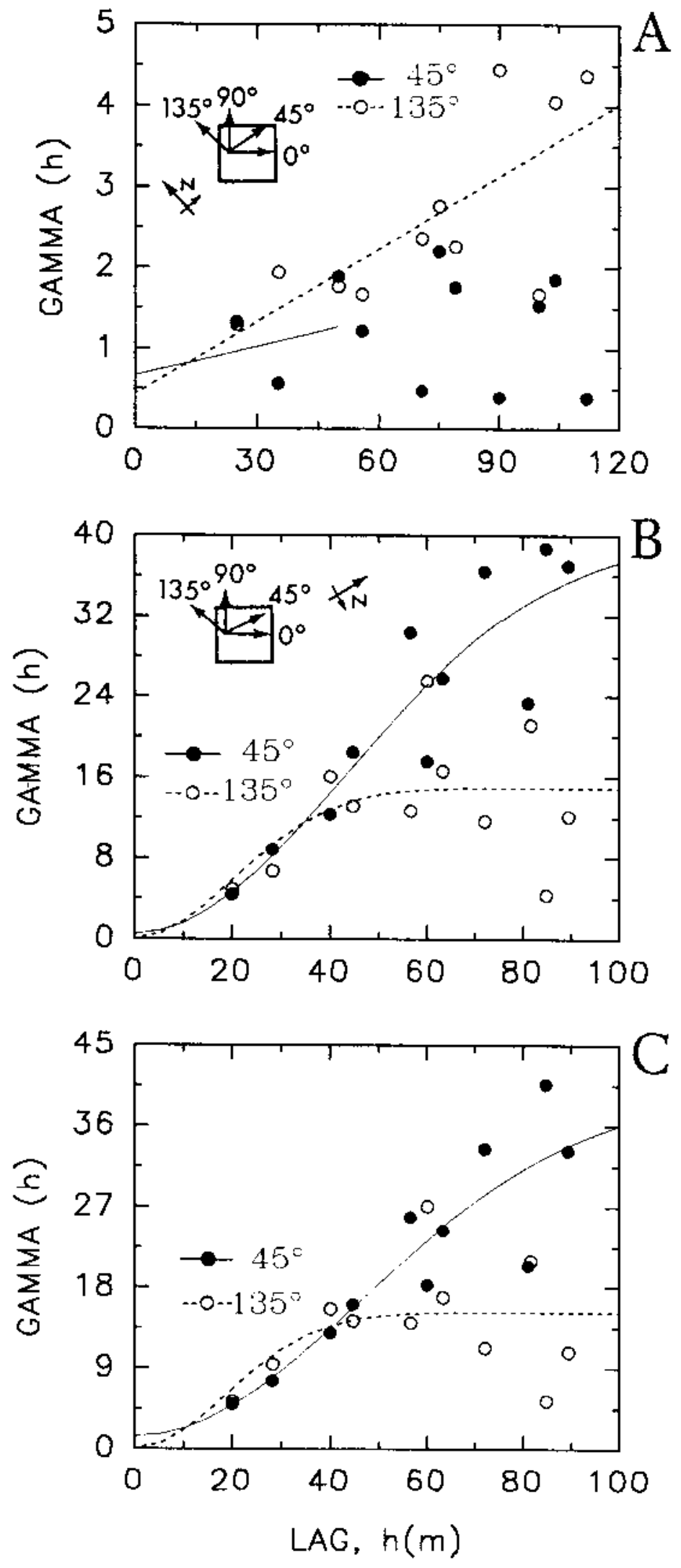

Fig. 3.

María V. López and José L. Arrúe

Efficiency of an Incomplete Block Design... 

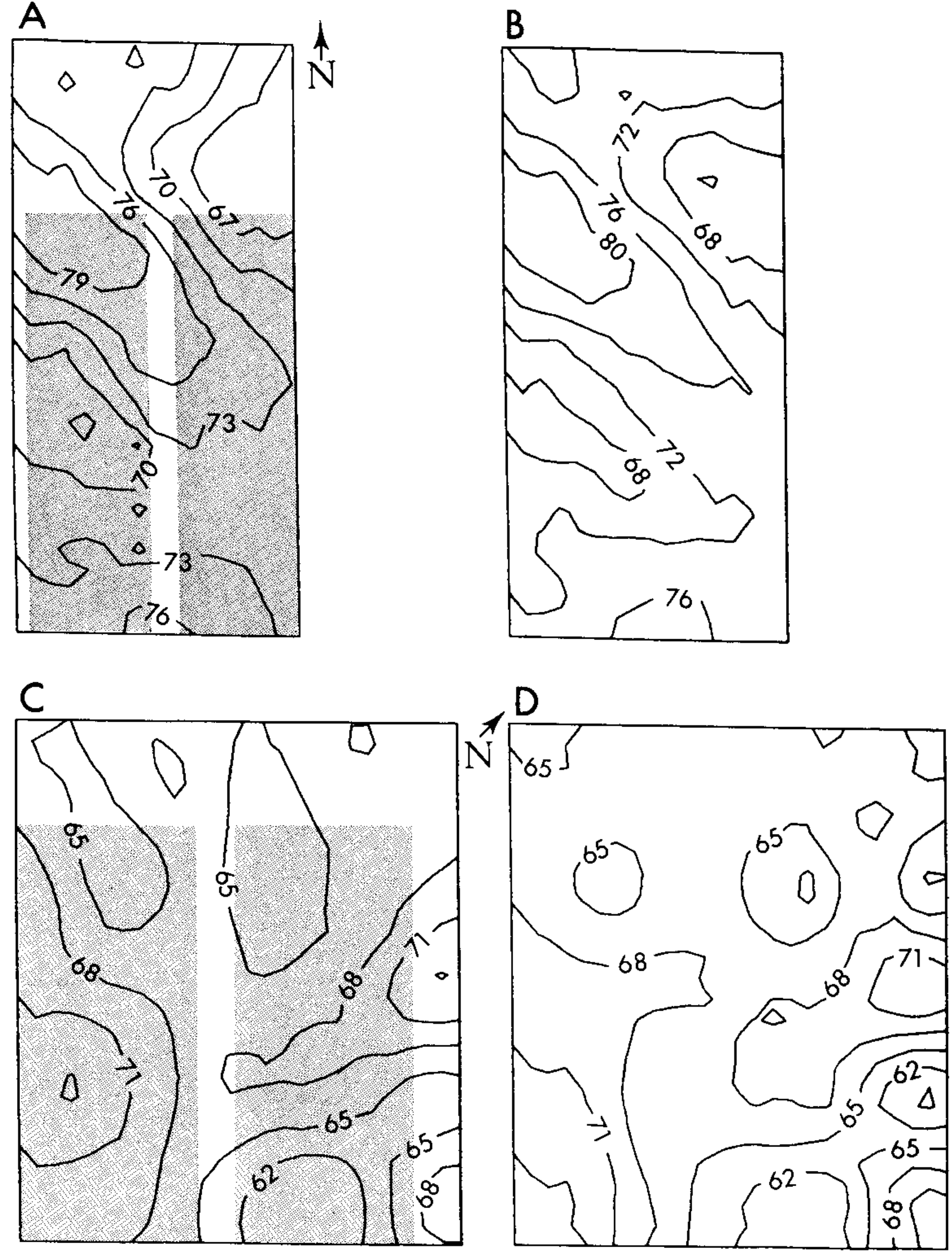

Fig. 4.

María V. López and José L. Arrúe

Efficiency of an Incomplete Block Design... 
